\section{DISPLAYING THE RESEARCHED BODY: Growing Cell Portraits in a Medical MUSEUM}

Louise Whiteley ${ }^{1,2}$, Karin Tybjerg ${ }^{1}$, Bente Vinge Pedersen ${ }^{1}$.

${ }^{1}$ Medical Museion, Faculty of Health and Medical Sciences, University of Copenhagen, 1310 Denmark.

${ }^{2}$ Novo Nordisk Foundation Center for Basic Metabolic Research, Faculty of Health and Medical Sciences, University of Copenhagen, 2200 Denmark.

E-mail: lowh@sund.ku.dk.

See <www.mitpressjournals.org/toc/leon/XX/X>for supplemental files associated with this issue.

Submitted: <leave for Editor to date>

Abstract

In Heirloom, artist Gina Czarnecki and scientist John Hunt grow portraits of the artist's daughters from their own cells, onto glass casts of their faces. This required the development of novel scientific techniques to allow the growth of human cells in a gallery. Heirloom was exhibited at Medical Museion as a part of EU Creative Europe project Trust Me, I'm an Artist. Here, we discuss three key issues raised by the artwork and its curation; (1) consent and ownership with regard to bodily materials, (2) biological portraiture and identity, and (3) DIY and depicting the future.

Keywords: skin, bioart, ethics, DIY, body, portraiture

The centerpiece of Heirloom [1] is an installation of two living portraits; skin cells from the artist's daughters gradually grow over traditionally produced glass casts of their faces. The glass casts are sunk down into two bioreactors filled with a pink liquid containing cells cultured from the girls' original samples plus growth serum, antibiotics and antifungals (see fig. 2 in Czarnecki and Hunt, this issue). The liquid is pumped around the closed system by a peristaltic pump, and kept at body temperature. When the layer of skin cells on the glass casts is thick enough, the portraits are removed and preserved for display (fig. 2).

Artist Gina Czarnecki wanted to investigate the idea of preserving her daughters' youthful appearance and offering it back to them in the future as a kind of inheritance: an artist's heirloom. This very personal work was also guided by an interest in the future of personalised medicine, developed through an interdisciplinary collaboration that interweaves technical, conceptual, and ethical concerns. Biomaterials specialist Professor John Hunt developed a novel system for Heirloom, the simplest possible set-up for the growth of human cells on this scale, in an exhibition environment, and in threedimensional form. This was aesthetically and practically essential for the artwork, but also acted as a methodological experiment in future techniques for reconstructive surgery. Its simplicity also points towards the potential for DIY cell therapy.

At Medical Museion in Copenhagen, the installation of growing portraits was presented as the second of five exhibition stations, overlaying the process of making the artwork with the future medical procedures it invites us to imagine (fig. 1). Each station had an imperative title, forming a series of instructions for an unknown user who might 'Cast', 'Grow', 'Use', 'Scan', and 'Bank' a face. Traditional casting methods were used to produce the beautiful glass faces for growing the cells - a cheaper solution for future medical use might be to add scans of our physical form to biobanks along with samples of our cells. The scans could then be $3 \mathrm{D}$ printed when required.

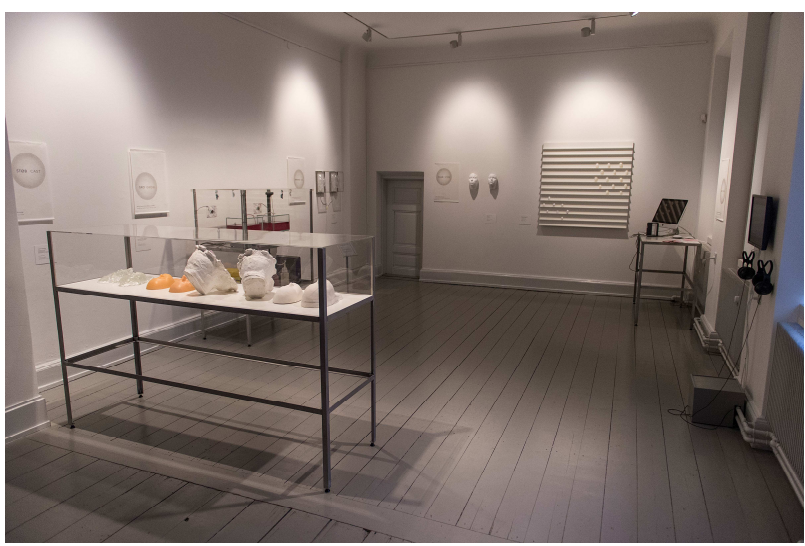

Fig. 1. Heirloom exhibition at Medical Museion: five stations overlay the artistic and scientific process of the work (C) Medical Museion, photographer Morten Skovgaard)

\section{Art in the medical museum}

Within science, technology, and medical museums, artistic practice can risk being instrumentalised as communication, illustration, or critique. At Medical Museion, we aim to allow all collaborators the space to develop their own practice, but with the understanding that no-one will remain unchanged by this process [2]. Heirloom has pushed this principle in new directions. The interplay of technical, conceptual, and aesthetic dimensions of the artwork sat in a shared space between the artist and her scientific collaborators. And the boundary between the artwork and its display was also fluid - for instance the display case for the growing skin portraits is not clearly part of an art installation, or a display case for a self-contained artwork (see fig. 2 in Czarnecki and Hunt, this issue).

One of the curatorial aims of Heirloom was to produce a comment on and continuation of the latest exhibition at Medical Museion, The Body Collected [3]. The Body Collected shows how human material has been collected for medical research over time, from foetuses in jars to blood samples in contemporary biobanks. Heirloom took over where The Body Collected left off, and the two exhibitions contextualised each other: Heirloom gave personal, living form to some of the ethical questions surrounding the largely unnamed, medically framed specimens in The Body Collected, and The Body Collected offered a material reminder to Heirloom of the long history of investigating and displaying human bodies and the different scales at which the body is understood.

Some of these issues were discussed in an ethics debate guided by an expert panel comprising media theorist and curator Jens Hauser, philosopher and historian Morten Hillgaard Bülow, art historian Christina Wilson, and doctor and researcher Ida Donkin. As with the other Trust Me, I'm an Artist debates, the aim was to bring discussion about the ethics of artists working with biological materials into the public realm. Additionally, such artworks can situate discussion of wider ethical and societal concerns about the biotechnologies they deploy. Below, we discuss three key examples, building on the ethics debate and curatorial discussions. 


\section{Consent and ownership}

The curators of The Body Collected wanted to include blood and DNA samples in the exhibition, but could not obtain these from a biobank. Instead, they donated their own and one of their children's samples. In Heirloom, the artist's use of her children's cells was conceptually key, but also avoided what would have been similar institutional barriers. Both exhibitions thus knit themselves into the history of self-experimentation as facilitator of biomedical or artistic innovation [4-6].

What does such personal, familial consent look like? Gina's daughters visited the lab, had non-invasive samples taken, and contributed to discussions about how the work should be displayed - but Gina was the one giving consent for their cells to be used. How can this consent be fully 'informed' when the artistic outcome is not yet known, and given the unequal power dynamic of parent over child? And how does consent evolve in the future - what happens if the girls change their minds about being 'on display'? These questions evoke related debates in medical research ethics. Typically, research participants give consent when donating a sample, and then waive the right to both ownership and feedback. Yet some researchers use and develop more participatory, ongoing forms of consent, particularly when individuals or communities might be identified or directly impacted by the research [7] - Heirloom could be seen as an extreme example of this scenario. Perhaps hybrid art projects like Heirloom can act as a crucible for developing new ethical approaches, as well as highlighting the barriers and illogics of existing institutional ethics procedures.

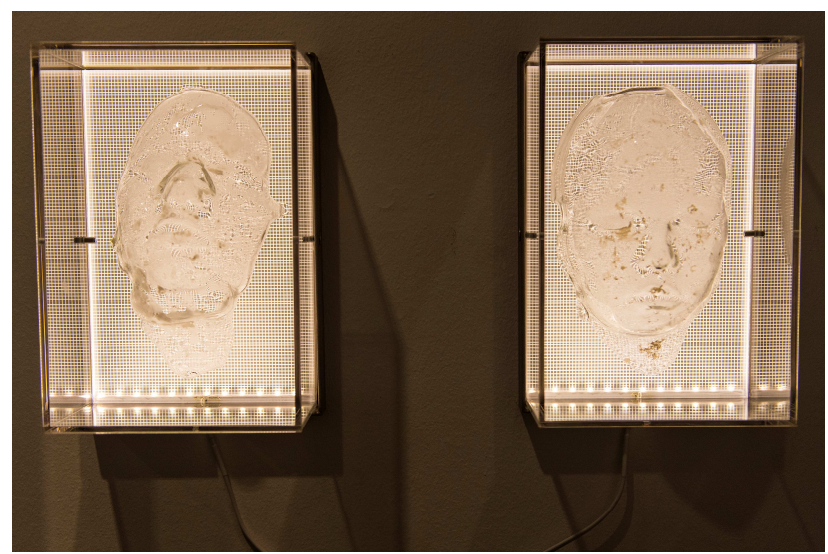

Fig. 2. The grown skin cell matrix is displayed as a pair of portraits, supported on glass casts and lit with an LED pane grid (C) Medical Museion, photographer Morten Skovgaard)

\section{Identity and portraiture}

Heirloom plays on notions of the portrait and personal identity (fig. 2). One expects a portrait to show a likeness of a person and reveal something of their character. Here cells from the sitters growing on casts of their faces seem to do more that just portray likeness - they reconstruct a version of the bodily self - but they don't quite reveal character. By capturing bodily material and physical appearance separately and reassembling them the artwork questions the scale at which identity is located, challenging the Aristotelian notion that matter and form are inseparable (the portraits of Marc Quinn offer related examples). Moreover, human faces are composed of many cell types - here a homogenous cell culture uncannily exceeds its typical scale; claiming new status in relation to the sitter's identity.

The play with scale opens up for multiple understandings of identity: Gina Czarnecki as mother and artist identifies the girls with their macroscopic bodies while the clinical professor and expert in biological materials identifies bodies at the cellular level. Yet at the same time the artwork inverts the professional identities of the artwork's creators: Gina cares for the cell solution of her children while John produces a unique piece of art rather than a reproducible experiment

\section{DIY and pressing the limits of the possible}

Cultivating an individual's cells for medical use is currently only possible in a lab, and is prohibitively expensive - future cell therapies may only be available to an elite few. Heirloom proposes an almost-DIY setup that could potentially be used at home, challenging industry control over regulated health technologies. This is mirrored in the framing of the exhibition handout as a 'manual', and was further explored through the hands-on workshops that invited artists, curators, and members of the museum audience to learn basic cell culture techniques.

DIY biology or 'biohacking' and bio-arts prompt anxiety about safety and regulation, often accompanied by an image of the artist or garage scientist recklessly pushing the limits of what is possible, without due consideration for the consequences. Yet medical research is also driven to find and exceed the limits of the physical body often without reflecting on the implications. Lab safety procedures may be in place, but possible impacts of physical enhancement on both individuals and health systems are often neglected.

Through its hybrid status as technological proposition, artistic investigation, and personal narrative, Heirloom offers a stage for considering all these potential implications of the technological future it depicts; from safety to the re-shaping of identity. But it is hard to know whether visitors will be excited by the notion of a future facial transplant or disturbed by the implication that youth is always desirable; upset by the idea of human cells manipulated in this way or excited by the possibility of trying it themselves. Indeed, our explicit intention was to resist both technological enchantment and dystopian visions, and to instead offer an unstable and ambiguous middle zone.

\section{Conclusion}

In Heirloom new bodily fragments are created, then researched whilst on display. This research is hard to pin down; it oscillates between scientific innovation, craft technique, and artistic strategy, destabilising the epistemological value and ethical status of the cells. In doing so, Heirloom brings to our attention the strange aesthetic and ethical status of all bodies that pass from research to display.

\section{References and Notes}

1. www.museion.ku.dk/heirloom and http://heirloom.ginaczarnecki.com

2. S. R. Davies, K. Tybjerg, L. Whiteley, and T. Söderqvist, "Co-Curation as Hacking: Biohackers in Copenhagen's Medical Museion," Curator: The Museum Journal 58 (2012) pp. 117-131.

3. K. Tybjerg, ed. The Body Collected (Copenhagen: Medical Museion, 2016)

4. L. K. Altman, Who Goes First? The Story of Self Experimentation in Medicine (Berkeley: University of California Press, 1987).

\section{5. http://biohackyourself.com/biohacking-101-why-self-experiment/}

6. J. Zylinska, The Cyborg Experiments: The Extension of the Body in the Media Age (London, UK: Continuum, 2002).

7. S. Banks et al. "Everyday ethics in community-based participatory research," Contemporary Social Science 8 (2013) pp. 263-277. 